\title{
Um Retrato da Residência Médica em Reumatologia no Brasil
}

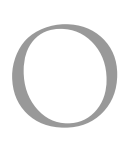

IV Encontro Nacional de Residentes e Docentes em Reumatologia (ENRDR), realizado em Itu-SP, em agosto de 2003, sob a coordenação da Comissão de Ensino da Sociedade Brasileira de Reumatologia (SBR), forneceu informações importantes sobre o estado atual dos programas de Residência Médica em Reumatologia (RMR) em nosso país.

Ainda em uma fase preparatória para o Encontro, foi feito um levantamento do número e características gerais dos serviços que oferecem RMR. Foram identificados 32 serviços reconhecidos pela Comissão Nacional de Residência Médica (CNRM), sendo 24 universitários (75\%) e 28 em instituições públicas (88\%). Embora todos os serviços tenham sido convidados a participar do levantamento, os dados a seguir correspondem aos 19 serviços (13 universitários - 68\%) que enviaram as respostas.

Estima-se em 90 o número de residentes nos programas de RMR (R1 + R2), numa média de 2,8 residentes por serviço. A relação entre o número de preceptores e residentes varia de 1 a 4,5, com média de 2,5 preceptores por residente. $\mathrm{O}$ número de leitos por serviço varia de $\mathrm{O}$ a 14 , com média de 5,5 leitos ( 2 leitos por residente). Os atendimentos mensais nos ambulatórios de reumatologia variam de 60 a 2000, com média de 528 atendimentos (188 atendimentos por residente). Dezesseis serviços possuem ambulatório de colagenoses (84\%) e 13 ambulatório geral (68\%). O número de ambulatórios específicos para as enfermidades prevalentes em reumatologia, entretanto, é bem menor: Osteoartrite 9 (47\%), Partes Moles 9 (47\%), Reumatologia Pediátrica 9 (47\%) e Osteoporose 5 (26\%). Mensalmente, encontram-se internados 12 a 40 pacientes reumáticos, com média de 20 pacientes ( 7 pacientes por residente).

Durante o Encontro, 48 professores, entre coordenadores dos programas de RMR, membros da Comissão de Ensino e palestrantes do evento, discutiram a RMR no Brasil. Inicialmente, alguns aspectos gerais da prática médica atual foram citados: queda na qualidade do ensino nas Faculdades de Medicina, colapso da infra-estrutura dos hospitais e unidades públicas, participação crescente das operadoras de planos de saúde como empregadoras de mão-de-obra médica (reduzindo a figura do médico como profissional liberal) e avanço acelerado do conhecimento médico.

Desde o início, ficou claro que não havia uma posição consensual sobre o objetivo maior do programa de RMR, qual seja, o tipo de profissional médico que se deseja formar. Um médico preparado para a prática de consultório, hospital geral ou universidade? Um clínico diferenciado, especializado nas infreqüentes doenças difusas do tecido conectivo, ágil na interpretação dos exames laboratoriais imunológicos e no emprego de imunossupressores e agentes biológicos? Um médico com formação voltada para o diagnóstico e manuseio das enfermidades musculosqueléticas mais freqüentes, capaz de interpretar os diferentes métodos de imagem e apto a prescrever uma órtese, um tratamento fisioterápico ou indicar uma cirurgia? Um profissional capaz de realizar procedimentos como capilaroscopia periungueal, punções e infiltrações articulares ou periarticulares, biópsias de glândula labial, músculo ou osso, artroscopia, densitometria óssea e ultrassonografia musculosquelética? É importante que ele conclua a RMR detendo todos esses conhecimentos? Existe tempo, condições materiais e humanas para a execução de um programa tão extenso? Como unir as características e os interesses dos serviços que oferecem RMR, com as expectativas dos residentes e os anseios da sociedade? Qual a formação necessária e possível para que ele, ao concluir a RMR, esteja habilitado para conseguir um emprego que o estimule profissionalmente e o remunere com dignidade?

Segundo os professores presentes, e de acordo com o levantamento prévio realizado, há uma tendência, na maioria dos serviços que formam residentes, para o atendimento de pacientes de colagenoses, em detrimento daqueles com osteoartrite, gota, fibromialgia, reumatismo de partes moles, patologias da coluna vertebral e osteoporose. A solução para este problema já começou a ser praticada por alguns serviços, não apenas por meio da criação dos referidos ambulatórios, como também do atendimento pelos residentes, sob a orientação dos preceptores, em postos de saúde do município ou Estado. Enfatizou-se a necessidade de uma melhor qualificação do residente de reumatologia para o tratamento da dor, em Medicina Física e Reabilitação e em procedimentos. Em razão da carência de alguns serviços, principalmente nos dois últimos itens, sugeriu-se que a SBR, por meio do Fundo de Auxílio à Pesquisa e Ensino em Reumatologia, auxiliasse no intercâmbio de alunos de diferentes programas. Foi consensual que punções, infiltrações e biópsias sinoviais deveriam fazer parte do treinamento de todo residente. Em conseqüência 
das limitações materiais e humanas, bem como do pequeno valor pago por estes procedimentos, o ensino de capilaroscopia periungueal, densitometria óssea, outras biópsias, artroscopia e confecções de órteses seria opcional.

A reunião realizada isoladamente com os 48 residentes e especializandos do segundo ano, presentes ao IV ENRDR, trouxe informações muito relevantes e instigantes. Mais de quatro quintos dos residentes consideraram sua RMR boa $(65 \%)$ ou ótima (18\%). As atividades práticas foram consideradas boas ou ótimas por 83\% (ambulatório) e 91\% (unidade de internação). Quanto ao aprendizado de procedimentos, entretanto, apenas $42 \%$ consideraram-no bom ou ótimo. Quanto aos estágios em outras especialidades, 60\% o fizeram em Pediatria, 58\% em Ortopedia, 57\% em Reabilitação, 41\% em Dermatologia e 19\% em Neurologia/Clínica de Dor. Setenta e nove porcento e 53\% passaram pelo laboratório e radiologia, respectivamente.

Embora $71 \%$ dos presentes respondessem que pretendiam realizar pós-graduação (mestrado ou doutorado), apenas $24 \%$ gostariam de seguir carreira universitária. Uma vez terminada a sua formação, $49 \%$ pretendiam permanecer em alguma capital, $36 \%$ pensavam em ir ou voltar para uma cidade do interior e $15 \%$ ainda não sabiam. Sessenta e oito por cento gostariam de abrir seu consultório particular, $8 \%$ gostariam de trabalhar em clínicas de multiespecialidades (convênios) e, como já foi dito, $24 \%$ gostariam de entrar para a vida acadêmica. Quando perguntados sobre que tipo de atividade profissional acreditavam que estariam envolvidos ao término da RMR, 46\% disseram que seria em clínicas de multiespecialidades (convênios), 34\% trabalhando como clínicos em plantões, $11 \%$ em carreira universitária e apenas 3\% teriam seu consultório próprio. Apesar destas discrepâncias, 91\% dos residentes estavam satisfeitos em ter escolhido a Reumatolgia como especialidade.

Quanto à participação da SBR na formação do residente, $24 \%$ acharam boa e $5 \%$ ótima. Dentre as sugestões oferecidas pelos residentes à SBR estão a criação da condição de sócio provisório, com anuidade reduzida, mudança no Programa Mínimo de RMR, com maior ênfase no diagnóstico e manuseio das doenças mais comuns, no tratamento da dor e em reabilitação. Solicitaram ainda que a SBR estimulasse a elaboração de Protocolos Terapêuticos das enfermidades reumatológicas, bem como facilitasse o acesso do residente a material didático impresso ou on-line. Por fim, sugeriram que a SBR organizasse uma avaliação trimestral do conteúdo teórico dos programas de RMR e que regionalizasse a Prova de Título de Especialista.

De acordo com a Resolução no 05/2002 da CNRM, publicada em sua versão final em 23 de dezembro de 2002, o programa de RMR passa a ter como pré-requisito dois anos de RM em Clínica Médica. Merece destaque no artigo 9 a obrigatoriedade de que nos $10 \%$ a $20 \%$ da carga horária, destinados às atividades teórico-complementares, deverão constar temas relacionados com Bioética, Ética Médica, Metodologia Científica, Epidemiologia e Bioestatística. Dos $80 \%$ a $90 \%$ da carga horária destinada ao treinamento em serviço, no primeiro ano, deverão ter um mínimo de $10 \%$ da carga anual em urgência e emergência e outros $10 \%$ em Medicina Física e Reabilitação. No segundo ano, a carga horária anual mínima em Medicina Física e Reabilitação deverá corresponder a $15 \%$.

Pelo que foi colocado pelos professores e residentes durante o IV ENRDR e para fazer frente à nova resolução do CNRM, faz-se necessário novas discussões visando adequar o Programa Mínimo de Residência Médica em Reumatologia da SBR à prática médica atual.

Agradecemos à dra. Cristina Costa Duarte Lanna e ao dr Marco Antônio P. Carvalho a ajuda na organização do ENRDR.

GERALDO DA ROCHA CASTELAR PINHEIRO Professor adjunto da disciplina de reumatologia da Faculdade de Ciências Médicas da Universidade Estadual do Rio de Janeiro, RJ 